\title{
DIVERSIFICACIÓN DE EXPORTACIONES: ¿ES CHILE DIFERENTE A AUSTRALIA Y NUEVA ZELANDA?
}

\author{
Hermann González B. \\ Centro Latinoamericano de Políticas Económicas y Sociales, Chile \\ Felipe Larraín B. \\ Pontificia Universidad Católica de Chile, Chile \\ Centro Latinoamericano de Políticas Económicas y Sociales, Chile \\ Óscar Perelló P. \\ University College London, United Kingdom \\ Centro Latinoamericano de Políticas Económicas y Sociales, Chile
}

\begin{abstract}
Hermann González es MA en Economía, Pontificia Universidad Católica de Chilem Chile. Coordinador macroeconómico del Centro Latinoamericano de Políticas Económicas y Sociales, Pontificia Universidad Católica de Chile (Clapes UC), Chile. Dirección: Avda. Libertador Bernardo O’Higgins 440, Santiago, Chile, CP 8331010. Email: hegonzal@uc.cl.
\end{abstract}

Felipe Larraín es PhD en Economía, Harvard University, EEUU. Profesor titular de la Facultad de Economía y Administración, Pontificia Universidad Católica de Chile, y miembro del Comité Ejecutivo del Centro Latinoamericano de Políticas Económicas y Sociales, Pontificia Universidad Católica de Chile (Clapes UC), Chile. Dirección: Avda. Libertador Bernardo O’Higgins 440, Santiago, Chile, CP 8331010. Email: flarrainb@uc.cl.

Óscar Perelló es MA en Economía, Pontificia Universidad Católica de Chile, Chile, y estudiante de doctorado del Departamento de Economía, University College London (UCL), United Kingdom. Investigador externo del Centro Latinoamericano de Políticas Económicas y Sociales, Pontificia Universidad Católica de Chile (Clapes UC), Chile. Dirección: Avda Libertador Bernardo O’Higgins 440, Santiago, Chile, CP 8331010. Email: oiperell@uc.cl.

Agradecemos los valiosos comentarios y sugerencias de dos árbitros anónimos y la asistencia en investigación de Catalina Badinella. 
RESUMEN: Este trabajo analiza el grado de diversificación de la economía chilena en relación con Australia y Nueva Zelanda durante el período 1990-2018, utilizando datos de exportaciones desagregados y distintas medidas de concentración. Australia y Nueva Zelanda se desarrollaron en un período reciente, comparten características estructurales con la economía chilena y, cuando tenían el nivel de ingreso de Chile, tenían mayores similitudes con la economía chilena que otros países que podrían usarse como modelo de desarrollo. Nuestros principales resultados indican que (i) Chile tiene un grado de concentración de exportaciones equivalente o inferior al de Australia, de acuerdo con la medición que se considere, pero superior al de Nueva Zelanda; (ii) el grado de concentración actual en Chile es similar al que tenía en 1990, a pesar del aumento observado durante el 'superciclo' de las materias primas; (iii) Australia y Nueva Zelanda han aumentado la concentración de sus exportaciones a lo largo del tiempo, lo cual estuvo asociado a una mayor participación de sus productos 'tradicionales'. La experiencia de Australia y Nueva Zelanda sugiere que la diversificación hacia bienes de mayor sofisticación económica no es una condición necesaria para el desarrollo de Chile, mientras que la evidencia económica sugiere enfocar la política comercial hacia potenciar el sector exportador y no tener la diversificación de exportaciones como un objetivo en sí mismo. Finalmente, se discuten políticas públicas alternativas, como potenciar la diversificación dentro del sector de recursos naturales e impulsar las exportaciones de servicios.

PALABRAS ClAVE: diversificación, exportaciones, desarrollo económico, ventajas comparativas, recursos naturales

RECIBIDO: mayo 2020 / ACEPTADO: agosto 2020

\section{EXPORTDIVERSIFICATION:ISCHILEDIFFERENTFROM AUSTRALIA AND NEW ZEALAND?}

ABSTRACT: This paper uses disaggregated export data and different concentration measures to analyse the degree of diversification of the Chilean economy in relation to Australia and New Zealand from 1990 to 2018. Australia and New Zealand developed in a recent period of time, they share structural characteristics with the Chilean economy and, when they had the per capita income level of Chile, they had greater similarities with the Chilean economy than other countries that could be used as development references. Our main results are that (i) Chile has a level of export concentration equivalent to or lower than Australia, according to the concentration index considered, but higher than that of New Zealand; (ii) the current level of concentration in Chile is similar to that of 1990, despite the increase observed during the commodity super-cycle; (iii) Australia and New Zealand have increased export concentration over time, which is related to an 
increase in their 'traditional' exports. The cases of Australia and New Zealand suggest that diversification towards products of greater sophistication is not a necessary condition for economic development in Chile, while the economic evidence suggests that trade policy should primarily focus on promoting the export sector and not on diversification itself. Finally, alternative public policies are discussed, such as promoting diversification within the natural resources sector and promoting service exports.

KEYWORDS: diversification, exports, economic development, comparative advantages, natural resources

RECEIVED: May 2020 / ACCEPTED: August 2020

\section{INTRODUCCIÓN}

E ste trabajo analiza el grado de diversificación de la economía chi1990-2018, utilizando datos de exportaciones desagregados y distintas medidas de concentración. Si bien la diversificación de exportaciones es un tema recurrente en el debate público, en general no se utiliza una medición que logre capturar la complejidad del sector exportador a lo largo del tiempo. Por su parte, organismos privados como las agencias clasificadoras de riesgo suelen indicar que la escasa diversificación de las exportaciones es una debilidad estructural de la economía chilena, pero tales análisis se reducen al porcentaje que representa la minería dentro del total exportado. ${ }^{1}$ Nuestros resultados permiten una medición más rigurosa del grado de diversificación de las exportaciones en Chile y compararlo en el tiempo con países que usamos como ejemplo de desarrollo.

La comparación con Australia y Nueva Zelanda es apropiada en al menos tres dimensiones. En primer lugar, Australia y Nueva Zelanda se desarrollaron en un período más reciente que otras potencias económicas, lo que facilita la comparación con el caso de Chile. Un segundo

\footnotetext{
${ }^{1}$ A modo de ejemplo, en su reporte de marzo de 2020, Fitch Ratings señala que una de las principales debilidades estructurales de Chile es su mayor dependencia de materias primas en relación a otros países con categoría $\mathrm{A}$, dado que la minería representa cerca del $50 \%$ de las exportaciones. Observaciones equivalentes, o sugerencias respecto de que una mejora en el rating crediticio requiere de un mayor grado de diversificación de las exportaciones, se encuentran en los reportes de Standard \& Poor y Moody's Investors Service durante 2019.
} 
punto se refiere a que Australia y Nueva Zelanda comparten características estructurales con la economía chilena, entre las que se cuentan el marco de política macroeconómica, la apertura comercial al mundo y la abundancia de recursos naturales. Por otro lado, se observan mayores similitudes entre las economías de Chile, Australia y Nueva Zelanda cuando estas últimas tenían un nivel de ingreso equivalente al de Chile, respecto de lo que ocurre con otros países que podrían usarse como modelos de desarrollo.

Utilizando datos de exportaciones desagregados provenientes de la UN Comtrade (2020), con cuatro dígitos de desagregación (HS-4) y con seis dígitos de desagregación (HS-6), se estiman tres de las principales medidas de concentración utilizadas en la literatura económica: el índice de Theil, el índice de Gini y el índice de Herfindahl. Nuestros principales resultados indican que (i) el grado de concentración de exportaciones actual en Chile es equivalente o inferior al de Australia, de acuerdo con la medición que se considere, pero superior al de Nueva Zelanda; (ii) el grado de concentración actual en Chile es similar al que tenía en 1990, a pesar del aumento observado durante el superciclo de las materias primas; y (iii) Australia y Nueva Zelanda han aumentado la concentración de sus exportaciones a lo largo del tiempo.

A nivel de productos, se observa que el aumento en los niveles de concentración en Australia y Nueva Zelanda está asociado a una mayor participación de sus exportaciones 'tradicionales', las que se refieren a la minería en Australia, y a los lácteos y carnes en Nueva Zelanda. En el caso de Chile, el cobre representa cerca de la mitad de la canasta de exportaciones ( $48 \%$ del total exportado), lo que es comparable a la suma de los principales productos mineros en Australia, que corresponden al carbón (20\% del total exportado), el hierro (19\% del total exportado) y el oro (6\% del total exportado). Lo anterior ilustra la importancia de utilizar medidas de concentración que consideren la totalidad del sector exportador; si bien Chile concentra un mayor porcentaje de sus exportaciones en un solo producto, a nivel agregado su nivel de concentración de exportaciones es similar al de Australia.

El caso de Nueva Zelanda ha sido utilizado frecuentemente como referencia de desarrollo para Chile, ya que solo en 1994 superó el PIB per cápita que tiene Chile en la actualidad y representa una meta de desarrollo más cercana que Australia. Al analizar la evolución de las 
exportaciones de Nueva Zelanda desde que tenía un nivel de ingreso equivalente al de Chile, se observa que sus exportaciones tradicionales aumentaron desde un $27 \%$ a un $34 \%$ del total exportado, impulsadas por los productos lácteos, mientras que sus exportaciones de manufacturas disminuyeron desde un $25 \%$ a un $16 \%$ del total exportado. Así, el desarrollo económico de Nueva Zelanda se dio en paralelo con un proceso de especialización en aquellas exportaciones en que contaba con ventajas comparativas, en desmedro de otros sectores que suelen asociarse con mayor sofisticación económica. ${ }^{2}$

En qué medida la diversificación de exportaciones es relevante para el desarrollo económico ha sido objeto de un largo debate en economía. Desde un punto de vista teórico, no existe una relación clara entre ambas variables. Los modelos ricardianos plantean que los países deben especializarse en aquellos bienes en que cuentan con ventajas comparativas, mientras que modelos más recientes sugieren que una relación causal entre diversificación y productividad podría ocurrir en ambas direcciones (Melitz 2003; Chaney 2008; Feenstra y Kee 2008). En términos empíricos se ha documentado una relación en forma de $\mathrm{U}$ entre ingreso per cápita y concentración de exportaciones, lo que se interpreta como evidencia en contra de un efecto causal de la concentración de exportaciones sobre el nivel de ingreso (Cadot, Carrère y Strauss-Kahn 2011). ${ }^{3}$ Considerando una amplia revisión de estudios empíricos, Cadot, Carrère y Strauss-Kahn (2013) plantean que no existe evidencia concluyente para los efectos de la diversificación de exportaciones. Por otro lado, Besedeš y Prusa (2011) muestran que el crecimiento de las exportaciones está asociado principalmente al margen intensivo, es decir, a un aumento en los productos ya exportados, mientras que la diversificación de exportaciones se

\footnotetext{
${ }^{2}$ Cabe señalar que, de acuerdo a Johnson (2014), el valor agregado de las exportaciones de manufacturas suele estar sobreestimado respecto de otras exportaciones. Además, algunos estudios sugieren que el crecimiento de la productividad en la agricultura puede ser tan significativo como en las manufacturas (Martin y Mitra 2001; Coelli y Rao 2005).

${ }^{3}$ Cadot, Carrère y Strauss-Kahn (2011) argumentan que, si existiera una relación causal desde la concentración de exportaciones hacia el nivel de ingreso, habría dos niveles de ingreso posible para cada nivel de diversificación (uno alto y uno bajo).
} 
asocia en mayor medida al margen extensivo (o variedad de productos exportados). ${ }^{4}$

Un contrapunto habitual se basa en el trabajo de Hausmann, Hwang y Rodrik (2007), el cual sugiere que exportar productos con mayor sofisticación tecnológica aumenta el crecimiento económico. ${ }^{5}$ Así, diversificar las exportaciones aportaría al desarrollo económico en la medida en que permita moverse hacia bienes más sofisticados. Sin embargo, una pregunta tanto o más relevante se refiere a la factibilidad de implementar esta estrategia para un país como Chile. Un estudio reciente de Lectard y Rougier (2018) plantea que desafiar las ventajas comparativas promoviendo exportaciones más sofisticadas podría tener consecuencias adversas para los países en desarrollo. En particular, los autores sugieren que estas estrategias pueden llevar a una industrialización espuria que, si bien aumenta el grado de sofisticación de las exportaciones, disminuye su valor agregado y limita el potencial de transformación tecnológica a futuro. Por otro lado, la experiencia neozelandesa sugiere que diversificarse hacia productos más sofisticados no es una condición necesaria para el desarrollo económico.

Un argumento relacionado se refiere a la llamada 'maldición' de los recursos naturales inspirada en el trabajo de Sachs y Warner (2001). Una alta concentración de recursos naturales puede aumentar la volatilidad de la economía (Cavalcanti, Mohaddes y Raissi 2015) y de los ingresos fiscales (Robinson, Torvik y Verdier 2017), además de estar asociada a mayores niveles de corrupción (Bhattacharyya y Hodler 2010) y clientelismo (Larraín y Perelló 2019). Si bien este punto es relevante para el caso de Chile, la literatura plantea que tales efectos son evitables si se establecen los marcos regulatorios adecuados (Boschini, Pettersson y Roine 2013; Robinson, Torvik y Verdier 2014). Así, más que desincentivar las exportaciones en base a recursos naturales, lo anterior sugiere seguir fortaleciendo la institucionalidad macrofinanciera que permite absorber la volatilidad externa, la institucionalidad fiscal

\footnotetext{
${ }^{4}$ Cadot, Carrère y Strauss-Kahn (2011) descomponen la concentración de exportaciones utilizando un índice de Theil y encuentran que las diferencias en concentración se explican principalmente por el margen extensivo.

${ }^{5}$ En términos simples, Hausmann, Hwang y Rodrik (2007) asignan mayor sofisticación tecnológica a un producto en la medida en que tal producto es exportado por países más desarrollados.
} 
que permite administrar las fluctuaciones en los ingresos fiscales y los estándares de probidad y transparencia que previenen efectos adversos sobre el sistema político.

A diferencia de lo que ocurre con la diversificación de exportaciones, existe un importante sustento teórico y empírico respecto de los beneficios de profundizar el comercio internacional. Como ha sido documentado por Feenstra (2018), los beneficios del comercio internacional van más allá de aprovechar las ventajas comparativas, ya que se expande la variedad de productos a la que pueden acceder los consumidores, permite el crecimiento de las empresas más productivas a través de las exportaciones y disminuye los precios mediante la competencia internacional. En términos cuantitativos, Costinot y Rodríguez-Clare (2018) señalan que las ganancias del comercio internacional están en un rango entre 2\% y $8 \%$ del PIB para el caso de Estados Unidos, pero tales ganancias serían aún mayores para una economía pequeña como la de Chile. ${ }^{6}$ Por otro lado, mientras no hay claridad respecto de la efectividad de las políticas públicas para diversificar las exportaciones, existe evidencia en favor de los programas para facilitar las exportaciones en su conjunto (Munch y Schaur 2018; Volpe y Carballo 2008).

La evidencia económica sugiere que la política comercial debiese centrarse en potenciar el sector exportador y no en diversificar las exportaciones como un objetivo en sí mismo. Aun si nos preocupáramos por la diversificación de exportaciones, como es habitual en el debate público, nuestros resultados sugieren que el grado de concentración en Chile es similar o inferior a uno de sus principales referentes de desarrollo, como es el caso de Australia; que el grado de concentración en Chile es similar a los niveles que tenía en 1990, a pesar del aumento observado durante el superciclo de las materias primas; y que tanto Australia como Nueva Zelanda se desarrollaron en décadas recientes en base al fortalecimiento de sus sectores tradicionales. Los casos de Australia y Nueva Zelanda son ilustrativos de modelos de desarrollo que se centran más en cómo producir que en qué producir, lo que les ha permitido agregar valor a sus exportaciones tradicionales.

\footnotetext{
${ }^{6}$ Costinot y Rodríguez-Clare (2018) argumentan que, en una economía de la magnitud de la de Estados Unidos, una parte significativa del comercio ocurre dentro del mismo territorio, lo que reduce los beneficios del comercio internacional respecto de economías de menor tamaño.
} 
Finalmente, como una manera de conciliar políticas públicas eficientes con el interés habitual que suscita la diversificación de exportaciones, se discuten dos políticas alternativas a la diversificación de exportaciones desde recursos naturales hacia sectores más sofisticados. Una opción se refiere a promover la diversificación de exportaciones dentro de cada sector productivo, lo que permitiría fortalecer los sectores que cuentan con ventajas comparativas al mismo tiempo que se aumentan las variedades exportadas. Larraín y Perelló (2020) muestran que este tipo de diversificación, dentro del sector de recursos naturales, puede contribuir positivamente al crecimiento del PIB. Otra opción se refiere a explotar las fortalezas institucionales que tiene Chile en materia económica para diversificarse hacia la exportación de servicios, al mismo tiempo que se explotan las ventajas comparativas en las exportaciones de bienes. En esa línea, Johnson (2014) sugiere que el valor agregado de las exportaciones de servicios a nivel global sería equivalente al que tienen las exportaciones de manufacturas.

El resto de este trabajo se estructura como sigue. La sección 1 analiza la pertinencia de comparar a Chile con Australia y Nueva Zelanda. La sección 2 presenta la metodología y datos utilizados. La sección 3 presenta los resultados para las distintas medidas de concentración y un análisis a nivel de productos. La sección 4 discute alternativas de política pública para Chile. La sección 5 concluye.

\section{1. ¿POR QUÉ COMPARAR A CHILE CON AUSTRALIA Y NUEVA ZELANDA?}

La comparación de Chile con Australia y Nueva Zelanda ha sido utilizada frecuentemente por distintos organismos públicos y privados. A modo de ejemplo, el Ministerio de Hacienda utilizó a Nueva Zelanda como horizonte de desarrollo en el Encuentro Nacional de la Empresa (Enade) en noviembre de 2018, lo cual fue reiterado en sucesivas presentaciones en las que también se incorporó a Australia como modelo de más largo plazo. ${ }^{7}$ En lo más reciente, el Ministerio de Hacienda ha formalizado el objetivo de seguir la trayectoria de desarrollo de Nueva Zelanda, destacando el dinamismo de su economía de mercado, su cli-

\footnotetext{
${ }^{7}$ Ver presentaciones del Ministerio de Hacienda (Larraín 2018a, 2018b, 2019).
} 
ma para hacer negocios y los altos estándares de probidad y eficiencia de su aparato estatal. ${ }^{8}$ Más allá de esta experiencia anecdótica, existen diversas razones económicas que fundamentan la comparación de Chile con Australia y Nueva Zelanda.

En primer lugar, Australia y Nueva Zelanda se desarrollaron en un período más reciente que otras potencias económicas, lo que facilita la comparación con el caso de Chile. En particular, las tecnologías que tenían disponibles al momento de desarrollarse, así como las condiciones globales que enfrentaban, son más comparables a las del Chile actual que las que experimentaron los países que se desarrollaron en décadas anteriores. Como se observa en la Tabla 1, Nueva Zelanda superó en 1994 el PIB per cápita que tenía Chile en 2018, mientras que Australia lo hizo en 1981. Por otro lado, en 2018, Nueva Zelanda tuvo un PIB per cápita (medido en dólares contantes de 2011 y a paridad del poder de compra) de US\$35.629, lo que representa una meta de desarrollo desafiante pero factible para Chile (US\$22.837), mientras que Australia representa un marco de referencia a más largo plazo (US\$46.544). En cuanto al tamaño de la economía, cabe señalar que Chile y Nueva Zelanda son economías pequeñas con un orden de magnitud similar en el contexto global (0,35\% y 0,24\% del PIB mundial, respectivamente), mientras que Australia cuenta con una economía de mayor tamaño (1,67\% del PIB mundial).

Un segundo punto se refiere a que Australia y Nueva Zelanda comparten características estructurales con la economía chilena, entre las que se cuentan el marco de política macroeconómica, la apertura comercial al mundo y la abundancia de recursos naturales. Como se observa en la Tabla 1, los tres países tienen un marco de política monetaria de metas de inflación y un régimen cambiario flexible. Chile y Australia son clasificados como países con flotación libre por parte del Fondo Monetario Internacional (FMI), lo que se traduce en que las intervenciones cambiarias son muy excepcionales; Nueva Zelanda, por su parte, tiene un régimen flotante, en el cual las intervenciones cambiarias ocurren con mayor frecuencia. Respecto de la política fiscal, los tres países cuentan con reglas fiscales para guiar su ejercicio. Además, Chile y Australia han establecido un Consejo Fiscal con autonomía durante los últimos años

\footnotetext{
${ }^{8}$ Ver entrevistas al ministro de Hacienda (Briones 2019, 2020).
} 
Tabla 1. INDICADORES MACROECONÓMICOS PARA CHILE, NUEVA ZELANDA Y AUSTRALIA

\begin{tabular}{|c|c|c|c|}
\hline & Chile & Nueva Zelanda & Australia \\
\hline \multicolumn{4}{|c|}{ Desarrollo económico y tamaño de mercado } \\
\hline $\begin{array}{l}\text { PIB per cápita } 2018 \\
\text { (US\$ PPP constantes 2011) }\end{array}$ & US\$22.837 & US\$ 35.629 & US\$ 46.544 \\
\hline $\begin{array}{l}\text { Año en que superó el PIB } \\
\text { per cápita de Chile } 2018^{*}\end{array}$ & - & 1994 & 1981 \\
\hline $\begin{array}{l}\text { PIB } 2018 \\
\text { (millones; US\$ corrientes) }\end{array}$ & US\$ 298.180 & US\$203.127 & US\$1.420.045 \\
\hline $\begin{array}{l}\text { Porcentaje del PIB mundial } \\
\text { (\%; US\$ corrientes) }\end{array}$ & $0,35 \%$ & $0,24 \%$ & $1,67 \%$ \\
\hline \multicolumn{4}{|c|}{ Marco de politica monetaria y fiscal } \\
\hline $\begin{array}{l}\text { Régimen monetario } \\
\text { (objetivo/rango) }\end{array}$ & $\begin{array}{l}\text { Metas de inflación } \\
\qquad(3 \%+/-1 \%)\end{array}$ & $\begin{array}{l}\text { Metas de inflación } \\
\qquad(2 \%+/-1 \%)\end{array}$ & $\begin{array}{l}\text { Metas de inflación } \\
(2 \% \text { a } 3 \%)\end{array}$ \\
\hline $\begin{array}{l}\text { Régimen cambiario** } \\
\text { (categorias FMI) }\end{array}$ & $\begin{array}{c}\text { Flexible } \\
\text { (flotación libre) }\end{array}$ & $\begin{array}{l}\text { Flexible } \\
\text { (flotante) }\end{array}$ & $\begin{array}{c}\text { Flexible } \\
\text { (flotación libre) }\end{array}$ \\
\hline $\begin{array}{l}\text { Regla fiscal } \\
\text { (categorias FMI; año } \\
\text { de creación 1ra. regla) }\end{array}$ & $\begin{array}{l}\text { Regla de balance } \\
\qquad(2001)\end{array}$ & $\begin{array}{l}\text { Regla de balance } \\
\text { Regla de deuda } \\
\text { (1994) }\end{array}$ & $\begin{array}{c}\text { Regla de balance } \\
\text { Regla de deuda } \\
\text { Regla de gasto } \\
\text { Regla de ingresos } \\
\text { (1985) }\end{array}$ \\
\hline $\begin{array}{l}\text { Consejo fiscal autónomo } \\
\text { (año de creación) }\end{array}$ & Si (2019) & No (en discusión) & Si (2012) \\
\hline \multicolumn{4}{|c|}{ Política comercial y exportaciones } \\
\hline $\begin{array}{l}\text { Apertura comercial }{ }^{* * *} \\
\text { (ranking, Global } \\
\text { Competitiveness Report 2019) }\end{array}$ & 5to / 141 paises & 4to / 141 paises & 3ro / 141 paises \\
\hline Principales productos exportados & Mineria & Lácteos / Carnes & Minería \\
\hline
\end{tabular}

Fuente: FMI (World Economic Outlook 2019, Annual Report on Exchange Arrangements and Exchange Restrictions 2018, Fiscal Rules Dataset 2017, Fiscal Council Dataset 2017). Penn World Table 9.1. Banco Central de Chile (2020), Reserve Bank of New Zealand, Reserve Bank of Australia, Foro Económico Mundial (The Global Competitiveness Report 2019), ONU (UN Comtrade 2020).

* Por superar se entiende el año en que se traspasa de manera definitiva ese nivel de ingreso. En el caso de Australia, se utilizan datos de la Penn World Table 9.1 que contienen un rango de años mayor al FMI.

** De acuerdo con la clasificación del FMI, tanto flotación libre como flotante se refieren a tipos de cambio determinados por el mercado, pero flotación libre considera un grado de flotación mayor. Un régimen cambiario se considera de flotación libre si las intervenciones cambiarias ocurren solo de manera excepcional, en presencia de condiciones de mercado particulares y mediante una justificación explícita por parte de la autoridad.

${ }^{* * *}$ Foro Económico Mundial. La apertura comercial considera las tarifas arancelarias, la complejidad de las tarifas arancelarias, las barreras no arancelarias al comercio y la eficiencia fronteriza. 
(2019 y 2012, respectivamente), mientras que en Nueva Zelanda su creación ha sido impulsada por el gobierno más recientemente. ${ }^{9}$ A nivel de exportaciones, predominan los productos vinculados a los recursos naturales, como es el caso de la minería en Australia y Chile, y los productos lácteos y carnes en el caso de Nueva Zelanda. En cuanto a la política comercial, las similitudes entre Chile, Australia y Nueva Zelanda son evidentes; de acuerdo con el Global Competitiveness Report 2019, Australia es el tercer país del mundo con mayor apertura comercial, seguido por Nueva Zelanda en el cuarto lugar y por Chile en el quinto lugar.

Un tercer punto se refiere a las similitudes entre las economías de Chile, Australia y Nueva Zelanda cuando estas últimas tenían un nivel de ingreso equivalente al de Chile, observándose mayores coincidencias que con otros países que podrían usarse como modelos de desarrollo. El Gráfico 1 ilustra la cercanía relativa entre las economías de Chile, Australia y Nueva Zelanda cuando tenían el mismo nivel de ingreso per cápita. Además, se ilustra la cercanía relativa con Corea del Sur y Singapur, siendo dos países que también superaron el ingreso per cápita de Chile en un período reciente (2001 y 1983, respectivamente). Las variables consideradas son (i) el porcentaje de exportaciones vinculadas a recursos naturales, definidas como la suma de exportaciones agrícolas, mineras y de alimentos de acuerdo a los World Development Indicators del Banco Mundial (2020b); (ii) el índice de capital humano, medido por los años de escolaridad y las tasas de retorno a la educación de acuerdo a la Penn World Table 9.1 (normalizado entre 0 y 1 ); ${ }^{10}$ (iii) la productividad de la economía, medida por la productividad total de factores de acuerdo a la Penn World Table 9.1 (normalizada entre 0 y $1) ;{ }^{11}$ (iv) la institucionalidad democrática, medida por el índice Polity2 del Polity IV Project, que evalúa la profundidad de las instituciones democráticas (normalizado entre 0 y 1); (v) la inversión como porcentaje del PIB, medida de acuerdo a las Penn World Table 9.1; y (vi) qué tan

\footnotetext{
${ }^{9}$ Para más información respecto del proceso de creación de un Consejo Fiscal en Nueva Zelanda, ver The Treasury, disponible en: https://treasury.govt.nz/news-and-events/news/ establishing-independent-fiscal-institution.

${ }^{10}$ Para más detalles respecto de la construcción y medición de las variables de la Penn World Table 9.1, ver Feenstra, Inklaar y Timmer (2015).

${ }^{11}$ Cabe señalar que la normalización utilizada por la Penn World Table 9.1 asigna un valor de 1 a la productividad total de factores de Estados Unidos, por lo que, en la práctica, esta es una medida de productividad relativa a los niveles de Estados Unidos.
} 
remota es la ubicación geográfica, lo cual se estima por el promedio de las distancias con los principales focos de comercio global (China, Estados Unidos y Europa), que se normaliza entre 0 y 1, donde 1 corresponde a la mayor distancia posible. ${ }^{12}$

El Gráfico 1 sugiere que, de acuerdo a diversos indicadores económicos, Chile se encuentra en un punto de partida mucho más similar al de Australia y Nueva Zelanda que al de Corea del Sur y Singapur, cuando estos países tenían un nivel de desarrollo equivalente. En los casos de Australia y Nueva Zelanda, predominaban las exportaciones de recursos naturales y, además, ambos países tienen una ubicación geográfica similar a la de Chile en términos de distancia con los principales focos de comercio global. Los niveles de capital humano en Chile son cercanos a los que tenían Australia y Nueva Zelanda, aunque se observa una distancia mayor al considerar los niveles de productividad e inversión respecto de Australia. Por otro lado, Singapur y Corea del Sur no eran exportadores de recursos naturales, por lo que su estructura económica ya era distinta cuando tenían el mismo nivel de desarrollo que Chile. En el caso de Corea del Sur, sus exportaciones vinculadas a recursos naturales eran menos del 5\% del total exportado, mientras que su distancia geográfica con los principales focos de comercio global es muy inferior a la de Chile. En el caso de Singapur, además de exportar solo un $15 \%$ de recursos naturales y tener una ubicación geográfica menos remota que Chile, sus niveles de inversión eran prácticamente el triple que los del Chile actual, sus niveles de capital humano eran mucho menores y sus instituciones políticas tenían bajos estándares democráticos.

Australia y Nueva Zelanda se desarrollaron en un período reciente, comparten características estructurales con la economía chilena en la actualidad y, cuando tenían el nivel de ingreso de Chile, tenían mayores similitudes con la economía chilena que otros países que podrían usarse como modelos de desarrollo. Lo anterior sugiere que utilizar a Australia y Nueva Zelanda como referencia de desarrollo para Chile es razonable desde el punto de vista económico, lo que hace particularmente relevante el análisis de la evolución del sector exportador de ambos países.

12 Considerar la distancia geográfica es importante dado que es un determinante de los flujos de comercio internacional (ver, por ejemplo, Chaney 2018) y de los patrones de concentración de exportaciones (Agosin, Álvarez y Bravo-Ortega 2012). 
Gráfico 1. SIMILITUDES ENTRE CHILE Y OTROS PAÍSES CUANDO TENÍAN UN INGRESO PER CÁPITA EQUIVALENTE

' Chile (2018)
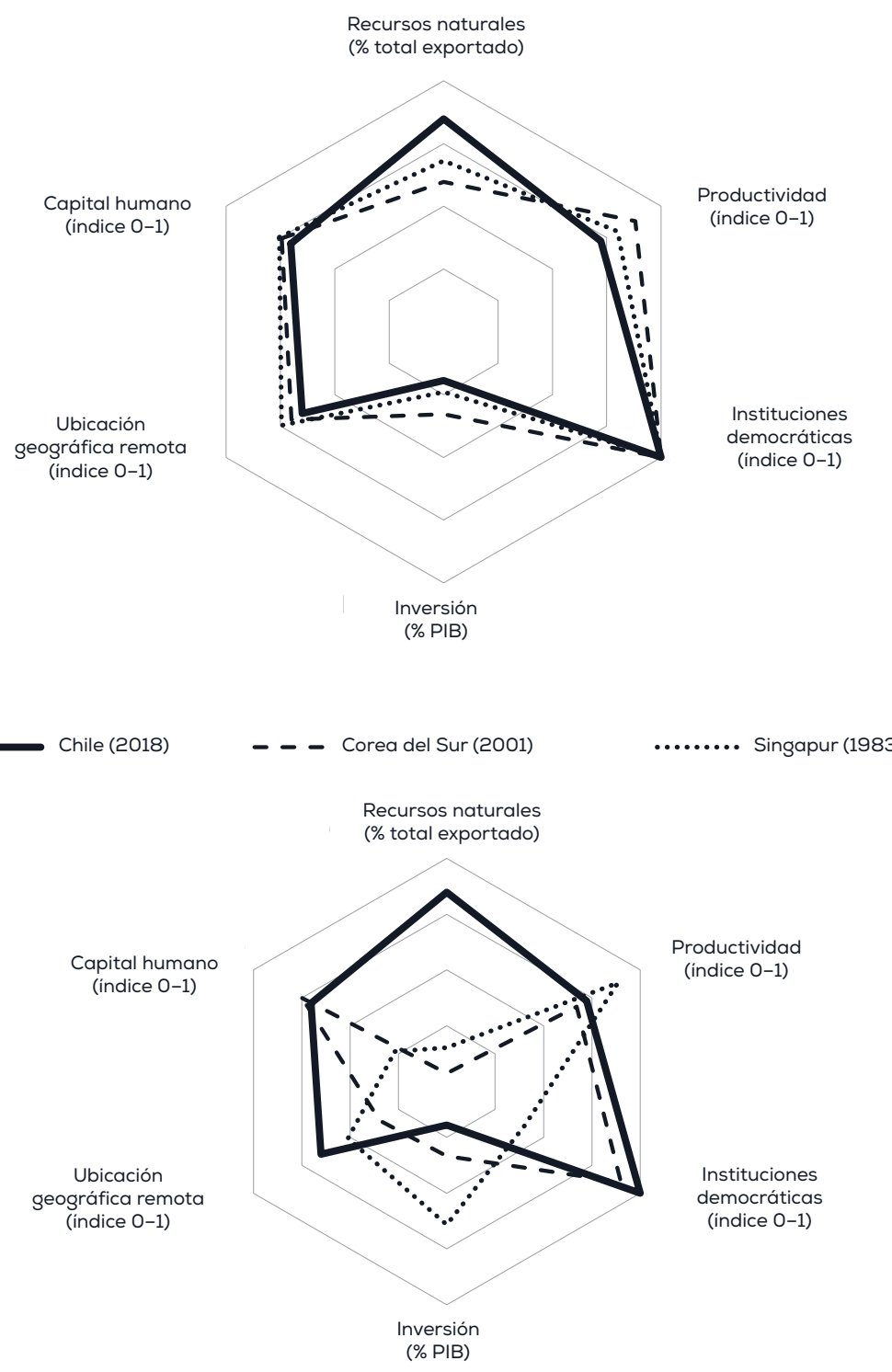

Fuente: Banco Mundial (World Development Indicators), Penn World Table 9.1, Polity IV Project. 


\section{METODOLOGÍA}

\section{Datos de exportaciones}

Es común que el debate respecto de la concentración de exportaciones se centre en el porcentaje que representa un sector productivo, y en particular un sector vinculado a los recursos naturales, sobre el total de exportaciones. Este análisis requiere poca información y es fácil de interpretar, por lo que es conveniente en términos prácticos, pero sus alcances son limitados. En primer lugar, al enfocarse en un solo sector productivo estas mediciones ignoran cómo se distribuye la participación relativa de los demás sectores. Aún más importante: estas mediciones omiten que dentro de cada sector productivo puede existir un alto grado de diversificación a nivel de productos. Así, la literatura económica en torno a la concentración de exportaciones ha optado por utilizar datos desagregados a nivel de productos para construir índices de concentración que consideren la totalidad del sector exportador (Agosin, Álvarez y Bravo-Ortega 2012; Cadot, Carrère y Strauss-Kahn 2011, 2013).

En línea con la literatura económica, este trabajo utiliza datos de exportaciones desagregados provenientes de la UN Comtrade, los cuales están clasificados de acuerdo con el Harmonized Commodity Description and Coding System (HS) y medidos a su valor comercial en dólares FOB. Se consideran dos niveles de desagregación. En primer lugar, se utilizan datos con cuatro dígitos de desagregación (HS-4), lo que en términos simples equivale a dividir las exportaciones de un país en torno a 1.000 líneas de exportación (o productos exportados). Luego, se utilizan datos con seis dígitos de desagregación (HS-6), los cuales corresponden al máximo nivel de desagregación disponible en la UN Comtrade y equivale a dividir las exportaciones en torno a 5.000 líneas de exportación. La razón para utilizar ambos niveles de desagregación se refiere a que, si bien datos más desagregados debiesen capturar de mejor manera las diferencias en los niveles de concentración entre países y a través del tiempo, también pueden hacer que las mediciones sean demasiado sensibles a variaciones pequeñas en algunos productos. Así, el uso de dos niveles de desagregación entrega mayor robustez a nuestros resultados. 


\section{Medidas de concentración de exportaciones}

La literatura económica reciente, aprovechando la disponibilidad de datos desagregados de exportaciones, se ha enfocado en construir índices que permitan capturar la concentración del sector exportador en su conjunto (Agosin, Álvarez y Bravo-Ortega 2012; Cadot, Carrère y StraussKahn 2011, 2013; Lederman y Klinger 2006). Además del tradicional índice de Herfindhal (IHH), que se utiliza habitualmente para estudiar la concentración de mercados, algunas medidas han sido tomadas desde la literatura sobre distribución del ingreso, como es el caso del índice de Theil y el índice de Gini (Cadot, Carrère y Strauss-Kahn 2013). Todos estos índices son equivalentes en términos conceptuales, en cuanto buscan medir la desigualdad que existe entre las observaciones de una distribución, ya sea que esta corresponda a la distribución de las ventas a nivel de empresas en un mercado, a la distribución de ingresos a nivel de individuos en un país o a la distribución de los montos exportados a nivel de líneas de exportación en un país.

Siguiendo la literatura reciente, en este estudio se incluyen las tres medidas de concentración antes mencionadas: el índice de Gini, el índice de Theil y el índice de Herfindahl (Cadot, Carrère y StraussKahn 2013). La única razón para incluir las tres medidas en el análisis se refiere a evaluar la robustez de nuestros resultados. En particular, si bien estos índices son equivalentes en términos conceptuales, la forma de implementarlos difiere en la práctica, por lo que se busca evitar que nuestros resultados respondan a las particularidades de la fórmula de cálculo utilizada. A continuación se describe cómo se construye cada uno de los índices de concentración utilizando datos de exportaciones.

Índice de Gini

El índice de Gini, habitualmente utilizado para medir la concentración del ingreso, ha sido incorporado por diversos estudios recientes para medir la concentración de exportaciones (Cadot, Carrère y Strauss-Kahn 2013). Formalmente, el índice de Gini mide el área entre la curva de Lorenz, que grafica los porcentajes acumulativos del ingreso respecto del número acumulativo de individuos (ordenados desde el individuo más pobre al más rico) y una curva hipotética en la cual el ingreso se distribuye de manera completamente equitativa entre los individuos. En el caso de la concentración de exportaciones, su formalización es 
idéntica, pero considerando la distribución de los montos exportados de cada producto. En cuanto a su interpretación, el índice de Gini se ubica en un rango de 0 a 1 , donde 1 representaría un sector exportador que está concentrado en un solo producto, mientras que 0 corresponde a un sector exportador donde se exporta el mismo monto para todos los productos.

En términos prácticos, existen numerosas fórmulas equivalentes para computar el índice de Gini en el caso de una distribución empírica, sea esta de ingresos, montos exportados u otra variable. Por ejemplo, Giorgi y Gigliarano (2017) documentan más de diez fórmulas equivalentes que han sido utilizadas en la literatura de la distribución del ingreso para computar el índice de Gini. En este caso, optamos por utilizar una de las fórmulas más utilizadas en la literatura de comercio internacional (Cadot, Carrère y Strauss-Kahn 2011, 2013) y que a la vez corresponde a una de las formulaciones más simples en términos algebraicos.

El procedimiento utilizado para el índice de Gini considera los siguientes pasos: (i) para cada país y año (cuyos subíndices se omiten para facilitar la exposición) se calcula la participación relativa que tiene cada línea de exportación (o producto exportado) sobre el total de exportaciones, $s_{i}$ (ecuación 1). (ii) Se ordenan las líneas de exportación de menor a mayor participación relativa y se computa la participación acumulada de las primeras $k$ líneas de exportación $\left(C_{k}\right)$, es decir, el porcentaje del total exportado que representan los $k$ productos con menor participación relativa (ecuación 2). (iii) Se computa el promedio de las diferencias entre las participaciones acumuladas de las líneas de exportación, $\bar{D}$ (ecuación 3). (iv) El índice de Gini se estima como la diferencia entre 1 y el promedio de las diferencias entre las participaciones acumuladas de las líneas de exportación (ecuación 4).

(1) $s_{i}=\frac{x_{i}}{\sum_{j=1}^{n} x_{j}}$
(2) $C_{k}=\sum_{i=1}^{k} s_{i}$
(3) $\bar{D}=\sum_{k=1}^{n}\left(C_{k}-C_{k-1}\right) / n$

(4) Gini $=1-\bar{D}$ 
Índice de Theil

El índice de Theil tiene un valor mínimo de 0, lo cual representa una distribución de montos exportados totalmente equitativa entre los distintos productos, mientras que su valor máximo, en principio, no tiene cota superior. ${ }^{13}$ Así, un mayor valor del índice de Theil se interpreta como una distribución de exportaciones más concentrada. En términos prácticos, las ecuaciones 5 y 6 presentan el cálculo para el índice de Theil del sector exportador. En primer lugar, para cada país y año se computa la media del monto exportado considerando todas las líneas de exportación, $\mu$ (ecuación 5). Luego, se calcula la razón entre el monto exportado de cada línea de exportación y la media del monto exportado, y se multiplica por el logaritmo de esa misma razón (ecuación 6). El índice de Theil corresponde a la sumatoria del producto anterior para todas las líneas de exportación dividido por el total de líneas de exportación.

(5) $\mu=\frac{1}{n} \sum_{j=1}^{n} x_{j}$
(6) Theil $=\frac{1}{n} \sum_{j=1}^{n} \frac{x_{j}}{\mu} \ln \left(\frac{x_{j}}{\mu}\right)$

Índice de Herfindahl

La ecuación (7) presenta el índice de Herfindahl (IHH) del sector exportador. Considerando un país y año en particular, se computa el porcentaje que representa cada línea de exportación dentro del total de exportaciones, $s_{i}$ (ver ecuación 1 en discusión sobre el índice de Gini). Luego, se calcula la sumatoria de las participaciones de todas las líneas de exportación elevadas al cuadrado. Además, la fórmula utili-

${ }^{13}$ En la práctica, al medir la concentración de exportaciones con el índice de Theil, sus valores medios suelen encontrarse entre 4 y 5 (ver, por ejemplo, Cadot, Carrère y Strauss-Kahn 2011). 
zada normaliza el índice, de manera que su valor se encuentre acotado entre 0 y 1 , lo que facilita su interpretación (ecuación 7). El IHH es igual a 1 si el sector exportador está concentrado en un solo producto, mientras que equivale a 0 si la participación relativa de cada producto es idéntica.

$$
\text { (7) } \quad \mathrm{IHH}=\frac{\sum_{i=1}^{n}\left(s_{i}\right)^{2}-1 / n}{1-1 / n}
$$

Finalmente, las tablas 2 y 3 presentan estadísticas descriptivas para los resultados obtenidos al computar cada una de las medidas de concentración (Theil, Gini e IHH), considerando los datos con nivel de desagregación HS-4 (1.000 líneas de exportación) y HS-6 (5.000 líneas de exportación), respectivamente. En particular, se presentan los resultados para Chile, Australia y Nueva Zelanda obtenidos a principios y fines del período 1990-2018, el promedio durante el período y la desviación estándar durante el período). Estos resultados se presentan y discuten con mayor detalle en la sección 3 .

Tabla 2. ESTAdíSTICAS DESCRIPTIVAS PARA MEDIDAS DE CONCENTRACIÓN

(Nivel de desagregación HS4; 1.000 líneas de exportación)

\begin{tabular}{cccccc}
\hline & & 1990 & 2018 & $\begin{array}{c}\text { Promedio } \\
1990-2018\end{array}$ & $\begin{array}{c}\text { Desviación } \\
\text { estándar }\end{array}$ \\
\hline Theil & Chile & 3,604 & 3,573 & 3,452 & 0,221 \\
& Australia & 2,817 & 3,761 & 2,965 & 0,458 \\
& Nueva Zelanda & 2,601 & 2,794 & 2,491 & 0,167 \\
Gini & Chile & 0,962 & 0,957 & 0,953 & 0,006 \\
& Australia & 0,926 & 0,958 & 0,928 & 0,021 \\
& Nueva Zelanda & 0,922 & 0,932 & 0,913 & 0,010 \\
IHH & Chile & 0,149 & 0,112 & 0,107 & 0,024 \\
& Australia & 0,038 & 0,112 & 0,056 & 0,030 \\
& Nueva Zelanda & 0,030 & 0,039 & 0,030 & 0,008 \\
\hline
\end{tabular}

Fuente: Elaboración propia en base a UN Comtrade (2020). 
Tabla 3. ESTADíSTICAS DESCRIPTIVAS PARA MEDIDAS DE CONCENTRACIÓN

(Nivel de desagregación HS-6; 5.000 líneas de exportación)

\begin{tabular}{lccccc}
\hline & & 1990 & 2018 & $\begin{array}{c}\text { Promedio } \\
1990-2018\end{array}$ & $\begin{array}{c}\text { Desviación } \\
\text { estándar }\end{array}$ \\
\hline Theil & Chile & 4,211 & 4,506 & 4,244 & 0,266 \\
Gini & Australia & 3,707 & 4,836 & 3,918 & 0,535 \\
& Nueva Zelanda & 3,277 & 3,549 & 3,172 & 0,190 \\
& Chile & 0,976 & 0,977 & 0,971 & 0,004 \\
\multirow{3}{*}{$\mathbf{H H} \quad$ Australia } & 0,952 & 0,975 & 0,955 & 0,014 \\
& Nueva Zelanda & 0,949 & 0,959 & 0,945 & 0,006 \\
& Chile & 0,116 & 0,108 & 0,097 & 0,024 \\
& Australia & 0,035 & 0,111 & 0,054 & 0,031 \\
& Nueva Zelanda & 0,020 & 0,029 & 0,020 & 0,006 \\
\hline
\end{tabular}

Fuente: Elaboración propia en base a UN Comtrade (2020).

\section{RESULTADOS}

\section{Diversificación de exportaciones en Chile, Australia y Nueva Zelanda}

Los gráficos 2 y 3 presentan nuestros resultados para el grado de concentración de exportaciones en Chile, Australia y Nueva Zelanda, utilizando datos con nivel de desagregación HS-4 (1.000 líneas de exportación) y HS-6 (5.000 líneas de exportación), respectivamente. En primer lugar, se observa que las exportaciones de Chile eran significativamente más concentradas que las de Australia y Nueva Zelanda en 1990, mientras que en 2018 tiene un grado de concentración de exportaciones equivalente o levemente inferior al de Australia, aunque superior al de Nueva Zelanda. Lo anterior responde a que el grado de concentración de la economía chilena en 2018 es similar al que tenía en 1990, mientras que tanto Australia como Nueva Zelanda han aumentado sus niveles de concentración durante las últimas décadas.

$\mathrm{Al}$ analizar el grado de diversificación en Chile a lo largo del tiempo, se observa una tendencia hacia la diversificación a comienzos de la década de 1990, lo que coincide con un período de fuerte apertura comercial; con un aumento de la concentración a partir de 2003, en línea con el superciclo de las materias primas; y con una nueva tendencia hacia la diversificación a partir de 2010, lo que coincide con el decaimiento del superciclo de las materias primas y también con la implementación de nuevas políticas comerciales destinadas a la facilitación 
Gráfico 2. CONCENTRACIÓN DE EXPORTACIONES EN CHILE, AUSTRALIA Y NUEVA ZELANDA (NIVEL DE DESAGREGACIÓN HS4: 1.000 LÍNEAS DE EXPORTACIÓN)

Concentración de exportaciones (Theil, HS4)

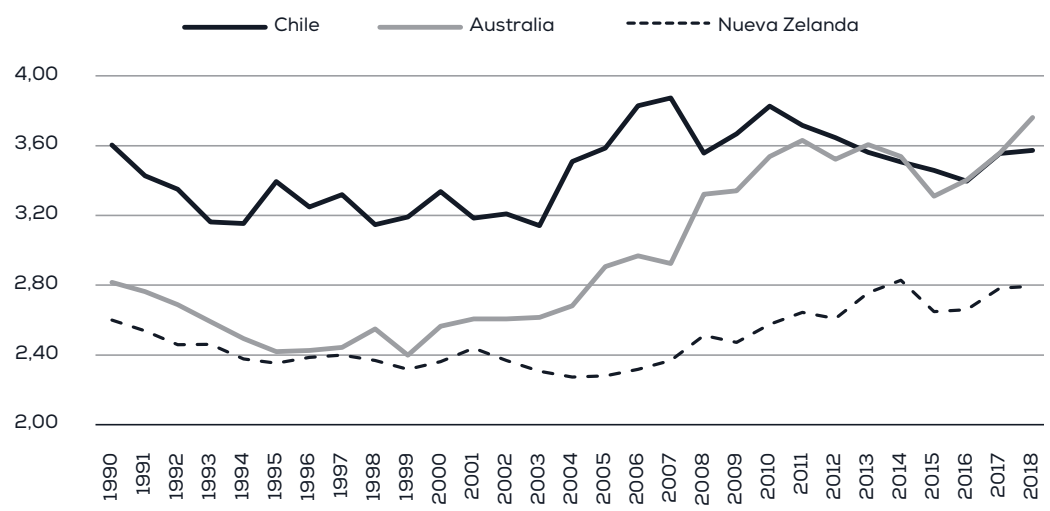

Concentración de exportaciones (Gini, HS4)

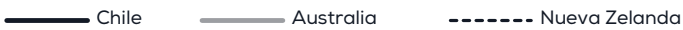

0,97

0,950

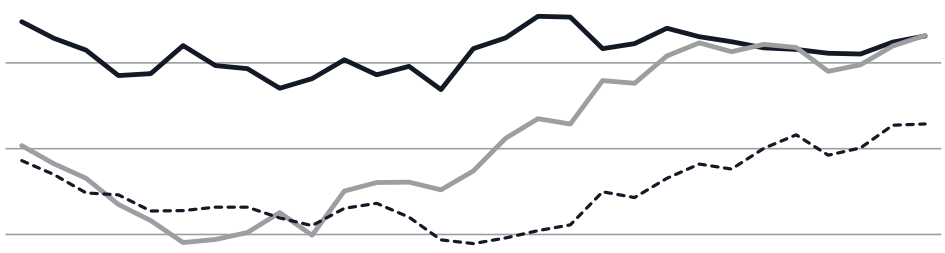

0,875

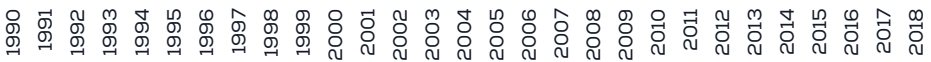

\section{Concentración de exportaciones (IHH, HS4)}
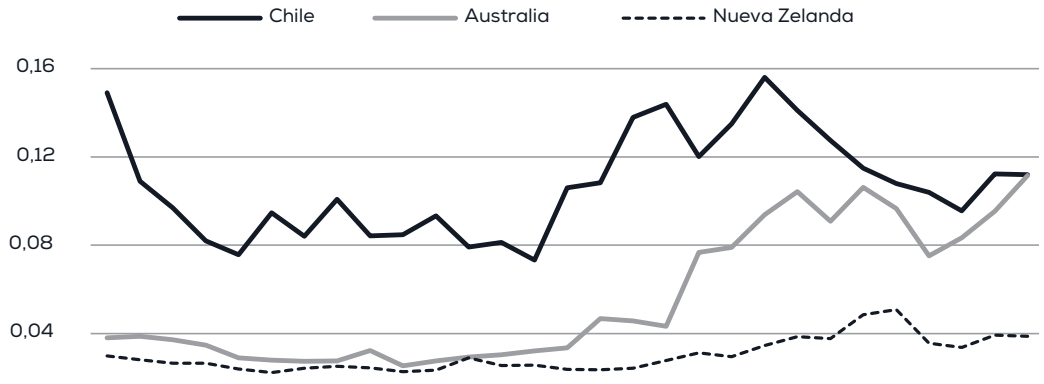
Gráfico 3. CONCENTRACIÓN DE EXPORTACIONES EN CHILE, AUSTRALIA Y NUEVA ZELANDA (NIVEL DE DESAGREGACIÓN HS6: 5.000 LÍNEAS DE EXPORTACIÓN)

Concentración de exportaciones (Theil, HS6)

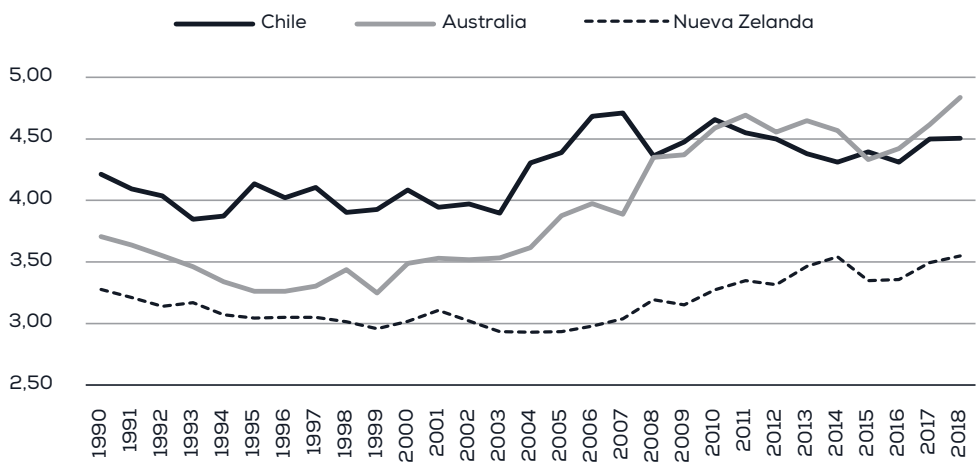

Concentración de exportaciones (Gini, HS6)

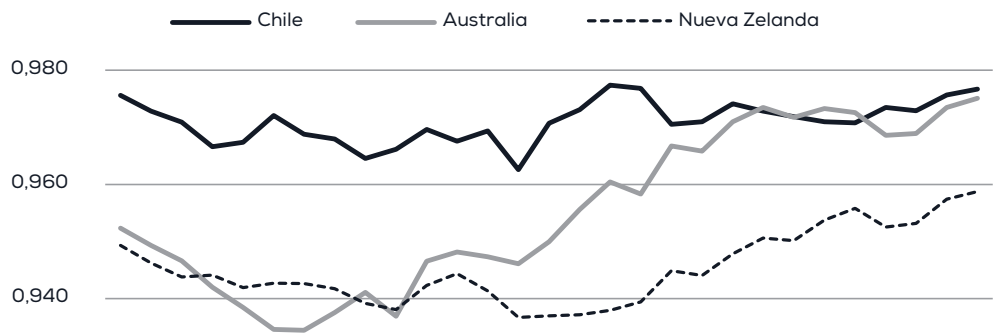

0,920

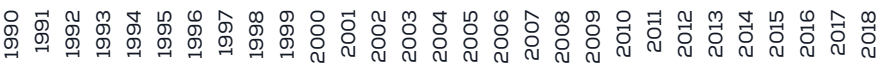
Concentración de exportaciones (IHH, HS6)

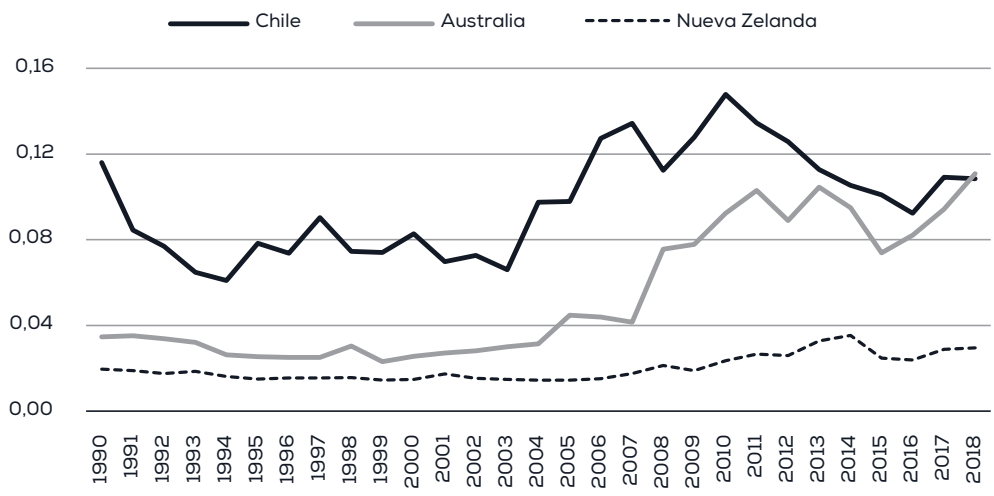

Fuente: Elaboración propia en base a UN Comtrade (2020). 
de exportaciones y al mejoramiento de los procesos logísticos. ${ }^{14}$ En los casos de Australia y Nueva Zelanda, la tendencia hacia la concentración de exportaciones está marcada por el superciclo de las materias primas, pero trasciende a lo que podría explicarse por este fenómeno y, en general, ha continuado hasta los años recientes.

Nuestros resultados ponen en perspectiva el grado de concentración de la economía chilena respecto de países desarrollados cuyas economías cuentan con características estructurales similares. Si bien es evidente la relevancia del cobre para la economía chilena, al analizar medidas de concentración que consideren la totalidad del sector exportador, no se observan diferencias significativas entre el grado de concentración de Chile y Australia en 2018. Otro aspecto relevante de nuestros resultados es que, si bien el grado de concentración en Nueva Zelanda es inferior al de Chile, este país ha tendido a concentrar sus exportaciones durante las últimas décadas. Como se aborda con mayor detalle a continuación, la tendencia a la concentración tanto en Nueva Zelanda como en Australia ha estado marcada por un aumento de la participación de sus exportaciones 'tradicionales', que corresponden a productos lácteos y carnes en el caso neozelandés, y a la minería en el caso de Australia, en desmedro de la participación del sector manufacturero en la matriz de exportaciones.

\section{Principales exportaciones en Chile, Australia y Nueva Zelanda}

Para complementar los resultados presentados en la sección 3, bajo el subtítulo "Diversificación de exportaciones en Chile, Australia y Nueva Zelanda", en esta sección se analiza cómo han evolucionado en el tiempo los principales productos exportados por cada país. En particular, se analiza en qué medida Chile, Australia y Nueva Zelanda han modificado los principales productos que componen su canasta de exportación y las tendencias a nivel de productos que podrían explicar la mayor concentración de exportaciones para los casos de Australia y Nueva Zelanda (gráficos 2 y 3 ).

\footnotetext{
${ }^{14}$ En 2010 se promulga el D.S. $N^{\circ} 1049$ que formaliza la operación del Sistema Integrado de Comercio Exterior (Sicex). Cabe señalar que existe evidencia económica a favor de los programas de fomento de exportaciones, especialmente cuando estos se refieren a facilitar el acceso de las firmas al mercado internacional (Munch y Schaur 2018; Volpe y Carballo 2008).
} 
El Gráfico 4 presenta la evolución de los principales productos exportados por cada país durante el período 1990-2018, utilizando datos de exportaciones que corresponden al nivel de desagregación HS-4 (1.000 líneas de exportación). ${ }^{15}$ Las principales exportaciones de Chile a este nivel de desagregación se refieren a productos del cobre (mineral de cobre, cobre refinado y otros productos sin refinar), observándose una tendencia al alza del mineral de cobre y una tendencia a la baja del cobre refinado, mientras que el cobre en su conjunto representa cerca de la mitad de la canasta de exportaciones. Por otro lado, se observa que en 2018 las exportaciones de Australia y Nueva Zelanda están concentradas principalmente en sus productos 'tradicionales'. En particular, las principales exportaciones de Australia corresponden a productos mineros (carbón, mineral de hierro y oro), mientras que las principales exportaciones de Nueva Zelanda corresponden a productos lácteos (leche, mantequilla y quesos) y carnes (bovinos y ovinos). Así, si bien el cobre predomina notablemente en las exportaciones chilenas, el análisis anterior sugiere que Australia y Nueva Zelanda no cuentan con canastas de exportación significativamente más sofisticadas.

En el Gráfico 4 se observa que las exportaciones tradicionales de Australia y Nueva Zelanda, además de no haber sido desplazadas por productos más sofisticados, han aumentado su participación en el tiempo. En el caso de Australia, tanto el carbón como el hierro aumentaron su participación relativa en la canasta de exportaciones, impulsados inicialmente por las condiciones favorables que ofrecía el superciclo de las materias primas, pero trascendiendo a ese lapso. En Nueva Zelanda, los productos lácteos aumentaron su participación en las exportaciones, mientras que las exportaciones de carnes mantuvieron su importancia relativa a través del tiempo.

El Gráfico 5 presenta la comparación de exportaciones entre Chile, Australia y Nueva Zelanda, pero agrupando los principales productos exportados. Como se mencionó anteriormente, en Chile las exportaciones de cobre mantienen una alta participación en las exportaciones y representan un $48 \%$ del total exportado en 2018. Sin embargo, esta participación no difiere significativamente del $44 \%$ que representó el car-

${ }^{15}$ Para facilitar la exposición, los nombres de los productos se han simplificado respecto de su etiqueta original en el Harmonized Commodity Description and Coding System (HS). 
Gráfico 4. EVOLUCIÓN DE LOS PRINCIPALES PRODUCTOS EXPORTADOS POR CHILE, AUSTRALIA Y NUEVA ZELANDA

Chile (\% del total de exportaciones)

Cobre refinado Mineral de cobre $\quad$ - . - . . Otros (sin refinar)

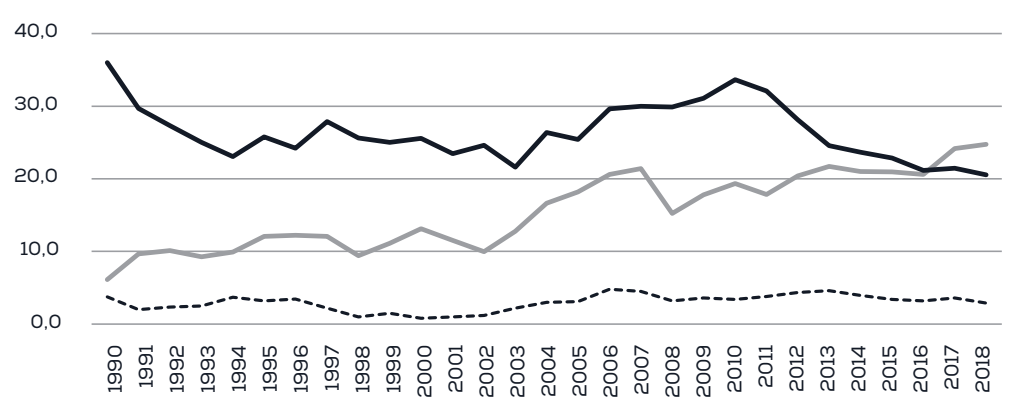

Australia (\% del total de exportaciones)

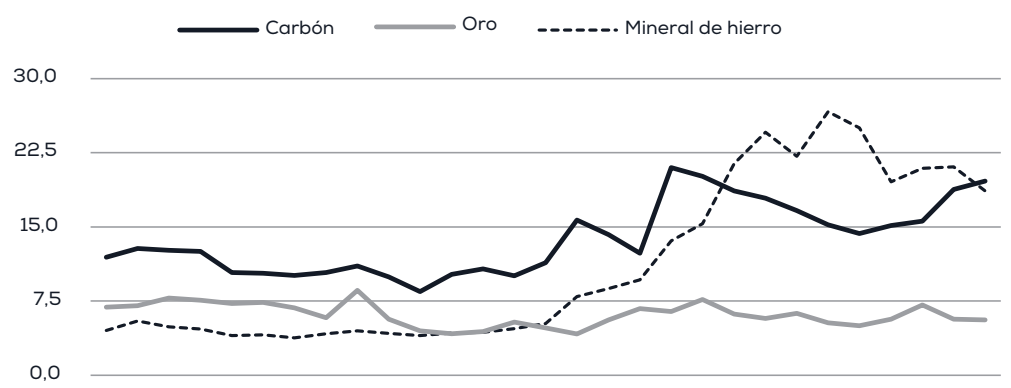

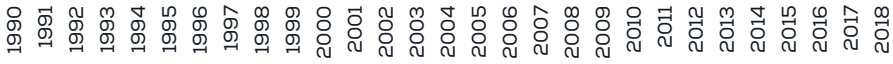

Nueva Zelanda (\% del total de exportaciones)

$\begin{array}{ll}\text { Leche } & \text { Mantequilla y quesos } \\ \ldots . . . . . . . & \text { Carne (ovinos) }\end{array}$

20,0

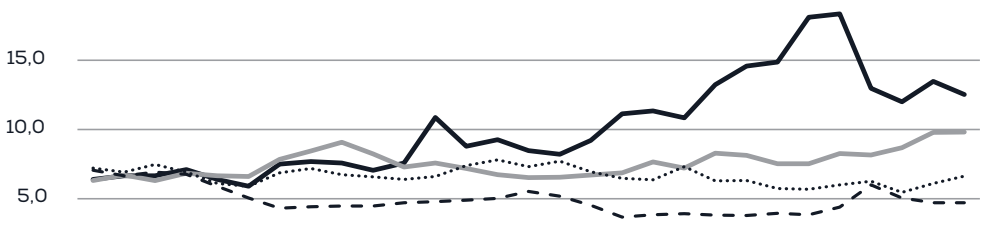

0,0

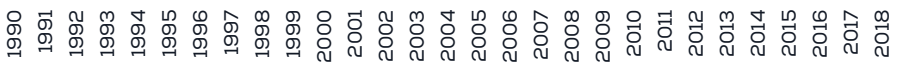

Fuente: UN Comtrade (2020). 
Gráfico 5. COMPARACIÓN DE LOS PRINCIPALES PRODUCTOS EXPORTADOS POR CHILE, AUSTRALIA Y NUEVA ZELANDA

Principales productos exportados (\% del total de exportaciones)
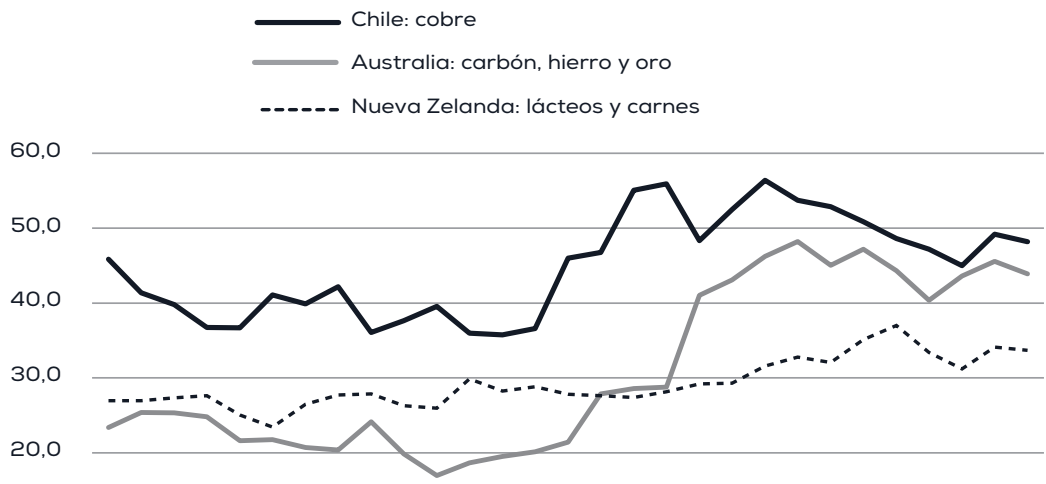

10,0

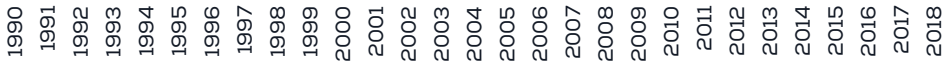

Fuente: UN Comtrade (2020).

bón, el mineral de hierro y el oro dentro de la canasta de exportaciones de Australia. En el caso de Nueva Zelanda se observa una diferencia de mayor magnitud, dado que los productos lácteos y carnes representaron en su conjunto un 34\% del total exportado en 2018.

En el Gráfico 5 también se observa con claridad cómo Australia y Nueva Zelanda han aumentado la participación de sus exportaciones tradicionales durante las últimas décadas. En el caso de Australia, el carbón, el mineral de hierro y el oro aumentaron su participación desde un $23 \%$ a un $44 \%$ del total exportado durante el período $1990-2018$, mientras que en Nueva Zelanda los lácteos y carnes subieron su participación desde un $27 \%$ a un $34 \%$ en el mismo lapso. Lo anterior sugiere que el mayor grado de concentración de exportaciones observado para Australia y Nueva Zelanda (gráficos 2 y 3), se explica por un proceso de especialización en sus exportaciones tradicionales.

\section{Nueva Zelanda como referencia de desarrollo para Chile}

El caso de Nueva Zelanda ha sido utilizado frecuentemente como referencia de desarrollo para Chile. Además de compartir las características estructurales antes descritas (ubicación geográfica remota, abundancia 
de recursos naturales, marco de política macroeconómica y apertura comercial), Nueva Zelanda representa una meta de desarrollo más cercana y realista que el caso de Australia. El nivel de desarrollo de Nueva Zelanda, medido por su ingreso per cápita en 2018 (US\$35.629), ${ }^{16}$ se encuentra a medio camino entre los casos de Chile (US\$22.837) y Australia (US\$46.544). Por otro lado, si bien tanto Australia como Nueva Zelanda se desarrollaron después que otras potencias económicas, el caso de Nueva Zelanda es particularmente reciente y hace menos de tres décadas tenía un nivel de ingreso per cápita similar al que tiene Chile hoy en día. ${ }^{17}$ Adicionalmente, Nueva Zelanda es un país relativamente pequeño y su economía, equivalente al 0,24\% del PIB mundial, tiene un tamaño similar al de la economía chilena $(0,35 \%$ del PIB mundial).

Considerando estos antecedentes, esta sección profundiza en el comportamiento del sector exportador de Nueva Zelanda a medida que el país aumentó su nivel de desarrollo y, particularmente, cuando tenía un nivel de ingreso comparable al de Chile. El Gráfico 6 presenta la evolución del PIB per cápita de Nueva Zelanda junto con la participación de las exportaciones tradicionales (comprendidas por productos lácteos y carnes) y la participación de las exportaciones manufactureras. Cabe señalar que el PIB per cápita de Nueva Zelanda en 1990 alcanzaba los US\$23.057, lo que es similar al nivel de ingreso que tuvo Chile en 2018 (US\$22.837). Sin embargo, luego de un período de recesión a comienzos de los noventa, Nueva Zelanda superó definitivamente el nivel de ingreso per cápita de Chile a partir de 1994.

El Gráfico 6 es ilustrativa respecto del comportamiento del sector exportador neozelandés durante el período en que ese país dio el salto al desarrollo. Cuando Nueva Zelanda tenía un nivel de ingreso equivalente al del Chile actual, la participación de sus exportaciones tradicionales y de sus exportaciones manufactureras era similar, y oscilaba en torno a un $25 \%$ del total exportado. Ambos sectores siguieron trayectorias divergentes de ahí en adelante. Las exportaciones tradicionales aumentaron sostenidamente su participación y representan un 34\% del total

\footnotetext{
${ }^{16}$ PIB per cápita medido en dólares constantes de 2011 y a paridad del poder de compra (FMI 2019).

17 En 1994, Nueva Zelanda superó de manera definitiva el nivel de ingreso per cápita que tenía Chile en 2018 (ver Tabla 1, sección 2).
} 
Gráfico 6. DESARROLLO ECONÓMICO Y EXPORTACIONES EN NUEVA ZELANDA

Nueva Zelanda 1990-2018

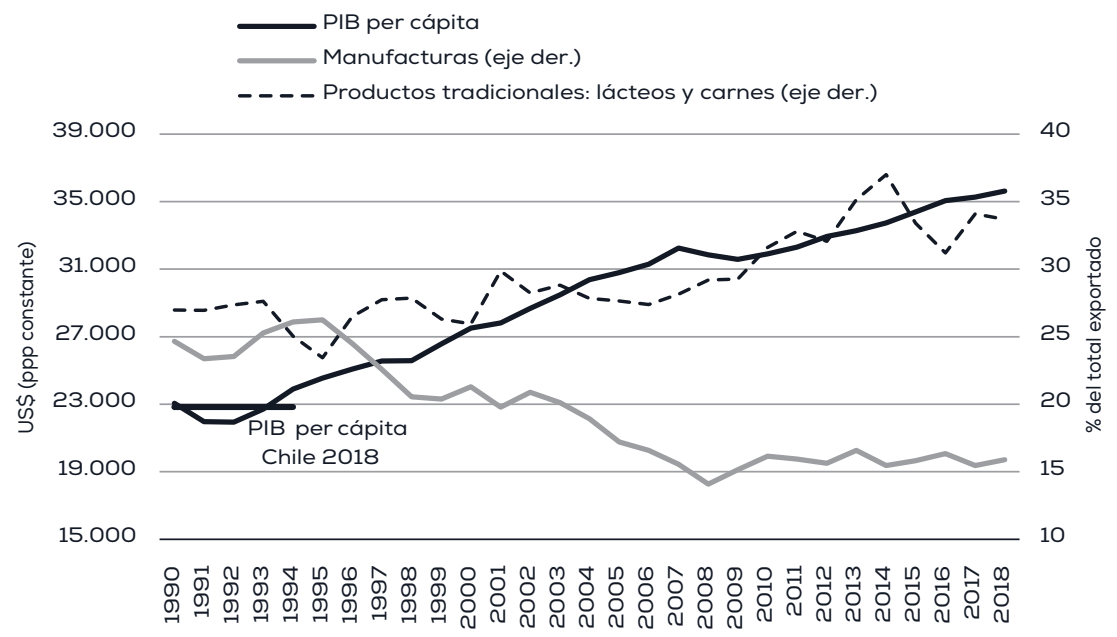

Fuente: FMI (World Economic Outlook 2019), UN Comtrade (2020).

exportado en 2018, mientras que las exportaciones manufactureras disminuyeron su participación y representan solo un $15 \%$ del total exportado en 2018.

Este análisis reafirma que el desarrollo económico de Nueva Zelanda no ocurrió mediante un desplazamiento de exportaciones hacia productos con mayor sofisticación económica, sino, por el contrario, ocurrió a la par de un proceso de especialización en sus exportaciones tradicionales (productos lácteos y carnes). Por otro lado, este proceso de especialización comenzó precisamente cuando Nueva Zelanda tenía un nivel de ingreso similar al del Chile actual y se extendió durante todo el período en que Nueva Zelanda dio el salto al desarrollo. Lo anterior sugiere que la diversificación hacia sectores más sofisticados no es una condición necesaria para el desarrollo económico, lo cual está en línea con la evidencia económica que encuentra que la diversificación de exportaciones no tiene un efecto causal sobre el nivel de ingreso de un país (Cadot, Carrère y Strauss-Kahn 2011, 2013). Considerando esta evidencia, así como lo reportado por Lectard y Rougier (2018) en cuanto a que estrategias que desafíen las ventajas comparativas para ex- 
portar productos más sofisticados pueden tener efectos adversos sobre algunos países en desarrollo, la opción de fortalecer el desarrollo exportador sin sesgos - aunque de ello se derive mayor participación de las exportaciones 'tradicionales' - es una estrategia de desarrollo factible para el caso de Chile.

Un último comentario se refiere a la trayectoria de desarrollo seguida por Nueva Zelanda desde que tenía un nivel de ingreso equivalente al de Chile. Si bien este trabajo se enfoca en la evolución de la concentración de exportaciones y en la composición de la canasta de exportaciones, es importante notar que el desarrollo de un país responde a la interacción de un amplio número de variables de orden económico, institucional y político. Por ejemplo, desde que Nueva Zelanda tenía un nivel de ingreso similar al del Chile actual, su índice de capital humano aumentó en promedio un $0,2 \%$ anual, su productividad total de factores un $0,3 \%$ anual, su fuerza laboral un $1,8 \%$ anual y su stock de capital un $3,7 \%$ anual. ${ }^{18}$ El significativo aumento del stock de capital sugiere que las políticas públicas de Nueva Zelanda fueron capaces de propiciar un ambiente adecuado para la inversión y no es casualidad que en la actualidad Nueva Zelanda sea el país con mayor facilidad para hacer negocios a nivel global (Banco Mundial 2020a). En ese sentido, la mayor competitividad de las exportaciones tradicionales en Nueva Zelanda interactuó con el crecimiento del stock de capital y es posible que ambas variables se reforzaran mutuamente. Así, la composición del comercio internacional no puede explicar por sí misma el desarrollo económico de un país, por lo que nuestros resultados deben ser comprendidos solo como un punto de partida para sacar lecciones que contribuyan al desarrollo de Chile.

\section{DISCUSIÓN: LINEAMIENTOS PARA POLÍTICAS PÚBLICAS}

La literatura económica analizada sugiere que la política comercial debiese centrarse en potenciar el sector exportador y no en diversificar las exportaciones como un objetivo en sí mismo. En particular, existe sustento teórico y empírico respecto de los beneficios de profundizar ${ }^{18}$ Las cifras de crecimiento de los factores productivos, el capital humano y la producti-
vidad total de factores provienen de la Penn World Table 9.1. 
el comercio internacional (Feenstra 2018; Costinot y Rodríguez-Clare 2018), así como sobre la efectividad de los programas para facilitar las exportaciones (Munch y Schaur 2018; Volpe y Carballo 2008), mientras que no hay evidencia contundente respecto de los efectos de la diversificación de exportaciones (Cadot, Carrère y Strauss-Kahn 2011, 2013). Además, Besedeš y Prusa (2011) encuentran que el crecimiento de las exportaciones está asociado principalmente con el margen intensivo, es decir, con un aumento en los montos transados en los productos ya exportados, y no con un aumento en la variedad de productos exportados. En cuanto a la opción de exportar productos más sofisticados, como plantean Hausmann, Hwang y Rodrik (2007), no es claro que sea una estrategia factible de implementar en el caso de Chile. En esa línea, Lectard y Rougier (2018) muestran que las estrategias que desafían las ventajas comparativas para exportar productos más sofisticados son una opción riesgosa para los países en desarrollo, y pueden terminar disminuyendo el valor agregado de sus exportaciones y limitando su capacidad de transformación tecnológica a futuro.

La evidencia encontrada en este artículo refuerza los lineamientos entregados por la literatura económica. Los casos de Australia y Nueva Zelanda sugieren que la diversificación hacia productos de mayor sofisticación económica no es una condición necesaria para el desarrollo económico de Chile. Ambos países exportaban mayoritariamente recursos naturales cuando tenían un nivel de ingreso similar al de Chile y, a medida que aumentaron su desarrollo económico, no aumentaron la sofisticación de su canasta de exportaciones. En ese sentido, ambos países se enfocaron más en cómo producir que en qué producir, fortaleciendo y agregando valor a sus exportaciones tradicionales, en las que contaban con ventajas comparativas. Por otro lado, aun si nos preocupáramos por la diversificación de exportaciones en sí misma, nuestros resultados sugieren que el grado de concentración en Chile es similar a uno de sus principales referentes de desarrollo, como es el caso de Australia, y que la concentración de exportaciones en Chile es similar a los niveles que tenía en 1990, a pesar del aumento propiciado por el superciclo de las materias primas.

Más allá de la evidencia analizada en este artículo, la diversificación de exportaciones continúa siendo una preocupación habitual en el debate público, así como por parte de organismos privados como las 
clasificadoras de riesgo. En un intento por conciliar políticas públicas eficientes con el interés habitual que suscita la diversificación de exportaciones, a continuación se discuten dos políticas que, sin buscar una diversificación forzosa hacia productos más sofisticados, podrían aumentar la diversificación de exportaciones al mismo tiempo que se potencian las ventajas comparativas de la economía chilena.

\section{Diversificación dentro de cada sector productivo}

Una alternativa a la diversificación hacia productos con mayor sofisticación económica se refiere a promover la diversificación de exportaciones dentro de cada sector productivo, lo que permitiría fortalecer los sectores que cuentan con ventajas comparativas, como es el caso de los recursos naturales en Chile, al mismo tiempo que aumentan las variedades exportadas. En ese sentido, Larraín y Perelló (2020) muestran que este tipo de diversificación dentro del sector de recursos naturales podría contribuir positivamente al crecimiento del PIB en países con abundancia de recursos mineros.

En el caso de Chile, el sector agrícola presenta un alto grado de diversificación de exportaciones, ${ }^{19}$ lo cual podría fortalecerse mediante la mejora de los procesos logísticos y la incorporación de nuevas tecnologías. Por su parte, las exportaciones industriales tienen una importante presencia de productos agroindustriales y de la industria silvícola, los que representan extensiones directas del sector de recursos naturales. ${ }^{20}$ Considerando la evidencia en favor de los programas de facilitación de exportaciones (Munch y Schaur 2018; Volpe y Carballo 2008), la política comercial puede contribuir a potenciar la diversificación de exportaciones en estos sectores, aumentando el valor agregado de las exportaciones tradicionales.

Lo anterior es lo que se conoce como una política comercial de segunda generación, la cual complementa a la política comercial de primera generación, comúnmente asociada a la reducción de las tarifas arancelarias. En esa línea, la formalización del Sistema Integrado de

\footnotetext{
${ }^{19}$ En el sector agrícola destacan las exportaciones de uva (19,4\% del total de exportaciones agrícolas), cerezas $(17 \%)$, manzanas $(11,1 \%)$, arándanos $(10,2 \%)$ y paltas $(5,1 \%)$. ${ }^{20}$ En el sector industrial destacan las exportaciones de salmón (16,2\% del total de exportaciones industriales), celulosa $(12,4 \%)$ y vinos $(5,6 \%)$.
} 
Comercio Exterior (Sicex) en 2010 y los avances en interoperabilidad portuaria concretados durante los últimos años, apuntan en la dirección correcta para permitir una mayor variedad de exportaciones dentro del sector de recursos naturales y/o en sectores relacionados. A modo de ejemplo, mientras en 2017 un $20 \%$ de las exportaciones chilenas se realizaba a través de Sicex, en 2019 más del 80\% del total exportado se realizó a través de esta plataforma.

Una arista adicional a considerar en esta estrategia es la llamada 'maldición' de los recursos naturales, que se refiere a los posibles efectos sobre la volatilidad económica y el sistema político de contar con una economía intensiva en recursos naturales. ${ }^{21}$ La literatura sugiere que tales efectos son evitables, pero que se deben establecer los marcos regulatorios y arreglos institucionales correspondientes (Boschini, Pettersson y Roine 2013; Robinson, Torvik y Verdier 2014). Así, la estrategia de agregar valor en el sector de recursos naturales debiese ir acompañada por una agenda constante de fortalecimiento institucional. En particular, sería recomendable seguir fortaleciendo la institucionalidad macrofinanciera que permite absorber la volatilidad externa, la institucionalidad fiscal que permite administrar la volatilidad de los ingresos fiscales, así como los estándares de probidad y transparencia que previenen efectos adversos sobre el sistema político.

\section{Chile como exportador de servicios}

Una opción complementaria se refiere a explotar las fortalezas institucionales que tiene Chile en materia económica para diversificarse hacia la exportación de servicios, al mismo tiempo que se explotan los sectores con mayores ventajas comparativas en las exportaciones de bienes. De acuerdo con el Global Competitiveness Report (World Economic Forum 2019), Chile es el país de Latinoamérica con mayor estabilidad macroeconómica y desarrollo financiero, así como el país con mayor adopción de tecnologías de la información y la comunicación (TIC),

${ }^{21}$ Como se mencionó en la introducción, ver Cavalcanti, Mohaddes y Raissi (2015) respecto de los efectos sobre la volatilidad de la economía; Robinson, Torvik y Verdier (2017), respecto de los efectos sobre la volatilidad del ingreso fiscal; Bhattacharyya y Hodler (2010), respecto de los efectos sobre la corrupción política, y Larraín y Perelló (2019), respecto de los efectos de clientelismo a nivel gubernamental. 
lo que representa un activo para desarrollar los servicios financieros y los servicios de telecomunicaciones, informática e información a nivel regional.

El comercio de servicios ha aumentado sostenidamente su importancia a nivel global durante las últimas décadas. Como se observa en el Gráfico 7, entre 1975 y 1995 el comercio de servicios incrementó solo modestamente su participación en la economía global, pasando de representar un $6 \%$ del PIB mundial a cerca de un $8 \%$. Sin embargo, después de 1995 su ritmo de crecimiento se aceleró significativamente y en 2018 pasó a representar más de 13\% del PIB mundial. Por otro lado, Johnson (2014) sugiere que el valor agregado de las exportaciones de servicios a nivel global está subestimado y que en la práctica sería cercano al valor agregado que aportan las exportaciones de manufacturas. Así, las exportaciones de servicios representan un nicho de rápido crecimiento a nivel global y con un alto valor agregado.

En Chile, el comercio de servicios representó un $8,2 \%$ del PIB en 2018, lo cual es superior al promedio de Latinoamérica (7,4\% del PIB), pero se ubica por debajo de Australia (9,9\% del PIB) y muy lejos de Nueva Zelanda, donde alcanzan un 15,4\% del PIB (World Development Indicators del Banco Mundial). Considerando las fortalezas institucionales de Chile en materia económica, la creciente importancia de los servicios a nivel global y la alta participación que alcanzan en un país con similitudes estructurales como es el caso de Nueva Zelanda, cabe al menos analizar si existe una oportunidad para potenciar a Chile como exportador de servicios a nivel regional.

El Gráfico 8 presenta la evolución reciente de las exportaciones de servicios en Chile. Se observa que, si bien las exportaciones de servicios totales disminuyeron en el margen, las exportaciones de servicios financieros y de servicios de telecomunicaciones, informática e información han tenido un crecimiento acelerado. ${ }^{22}$ Durante los últimos cinco años, las exportaciones de servicios financieros han crecido, en promedio, un $8,2 \%$ anual, mientras que las exportaciones de servicios de telecomunicaciones, informática e información han crecido, en promedio, un 7,4\% anual, siendo las dos categorías de servicios con mayor

${ }^{22}$ La caída en las exportaciones de servicios totales en los años reciente se explica, principalmente, por una fuerte disminución en las exportaciones de servicios de transportes (Banco Central de Chile 2020). 
Gráfico 7. EVOLUCIÓN DEL COMERCIO DE SERVICIOS A NIVEL GLOBAL (EXPORTACIONES E IMPORTACIONES)

\section{Comercio de servicos a nivel global}

(\% del PIB mundial)

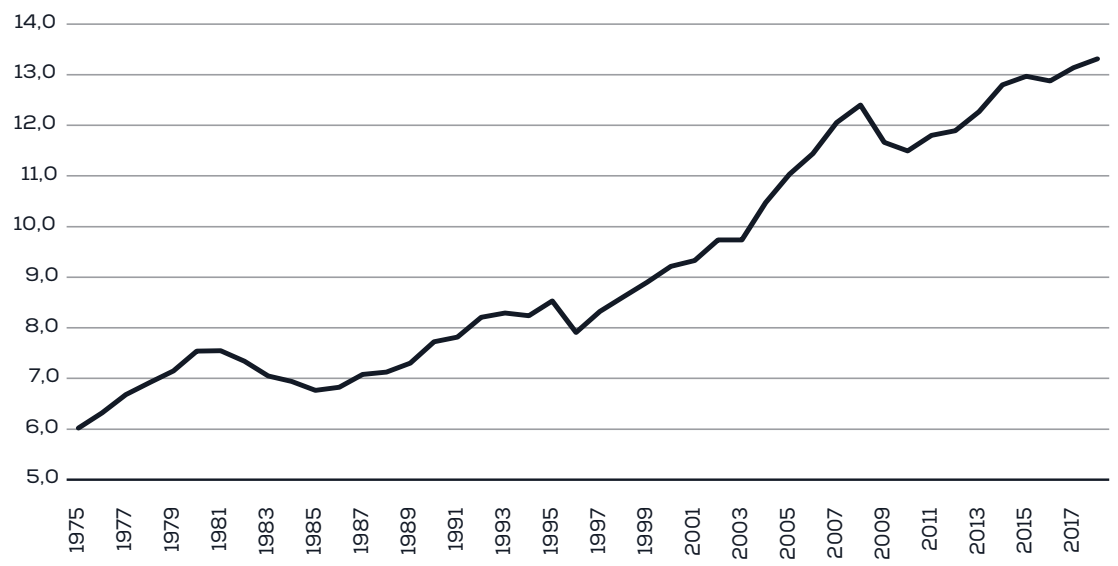

Fuente: Banco Mundial (World Development Indicators).

Gráfico 8. EXPORTACIONES DE SERVICIOS FINANCIEROS, SERVICIOS DE TELECOMUNICACIONES, INFORMÁTICA E INFORMACIÓN Y SERVICIOS TOTALES EN CHILE

\section{Chile. Exportaciones de servicios} (millones de US\$)

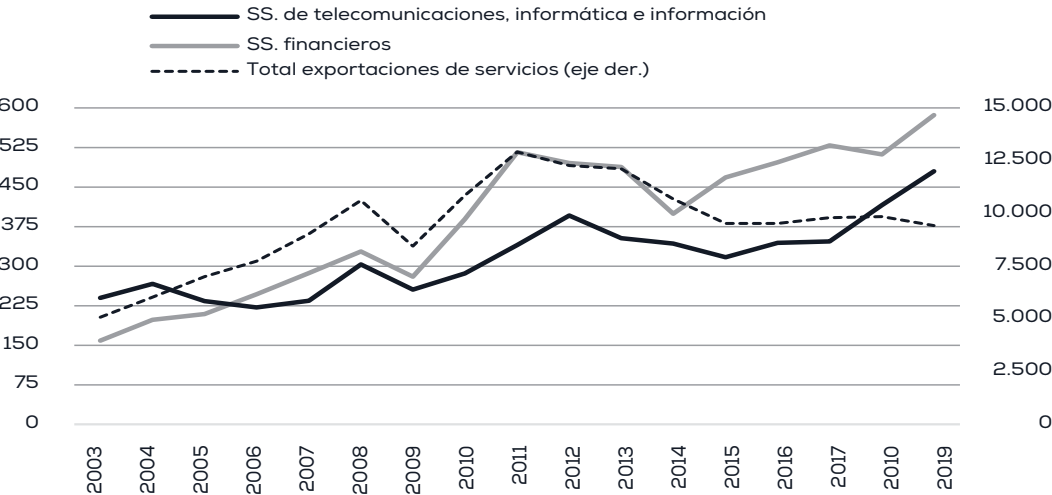

Fuente: Banco Central de Chile (2020) 
crecimiento. A pesar de este rápido crecimiento, el orden de magnitud de las exportaciones de servicios financieros y de las exportaciones de servicios de telecomunicaciones, informática e información continúa siendo bajo, alcanzando los US\$586 millones $(6,2 \%$ del total de servicios exportados) y los US\$480 millones $(5,8 \%$ del total de servicios exportados), respectivamente. El análisis anterior sugiere que la contribución de estas exportaciones de servicios al desarrollo económico de Chile podría llegar a ser significativamente mayor.

\section{CONCLUSIONES}

En primer lugar, nuestro trabajo formaliza la comparación de Chile con Australia y Nueva Zelanda, y provee fundamentos económicos para utilizar a estos países como horizonte de desarrollo. Tras un análisis riguroso del marco de política macroeconómica de Chile, Australia y Nueva Zelanda, se evidencian claras semejanzas a nivel de política monetaria, de política fiscal y de política comercial. Por otro lado, al analizar las economías de Australia y Nueva Zelanda cuando tenían un nivel de ingreso equivalente al de Chile, se observan mayores similitudes con la economía chilena respecto de otros países que podrían usarse como referencia de desarrollo, como los casos de Corea del Sur y Singapur. En particular, destaca la similitud de Chile, Australia y Nueva Zelanda en términos de exportaciones de recursos naturales y de su ubicación geográfica remota.

Un segundo punto se refiere a caracterizar el grado de concentración de exportaciones en Chile a lo largo del tiempo y ponerlo en perspectiva respecto de Australia y Nueva Zelanda. Nuestros resultados muestran que Chile tiene un grado de concentración de exportaciones similar al de Australia, pero superior al de Nueva Zelanda. Así, si bien el cobre continúa representando un alto porcentaje de la canasta de exportaciones, la concentración de exportaciones en Chile es similar a uno de sus principales referentes de desarrollo, como es el caso de Australia. Por otro lado, el grado de concentración de exportaciones en Chile es similar al que tenía en 1990, por lo que no ha habido un aumento sostenido de la concentración a lo largo del tiempo, a pesar del aumento experimentado durante el superciclo de las materias primas. 
Un tercer punto se refiere a la trayectoria de exportaciones seguida por Australia y Nueva Zelanda a medida que aumentaron su nivel de desarrollo económico. Nuestros resultados muestran que tanto Australia como Nueva Zelanda aumentaron la concentración de sus exportaciones, lo que se explica por una mayor especialización en sus productos 'tradicionales'. Ambos países exportaban mayoritariamente recursos naturales cuando tenían un nivel de ingreso similar al de Chile y, a medida que aumentaron su desarrollo económico, no aumentaron la sofisticación de su canasta de exportaciones. Así, los casos de Australia y Nueva Zelanda sugieren que la diversificación de exportaciones hacia sectores de mayor sofisticación económica no es una condición necesaria para el desarrollo económico.

Un cuarto punto se refiere a que la evidencia encontrada para Australia y Nueva Zelanda refuerza los lineamientos que entrega la literatura económica para el caso de Chile. En la literatura económica no existe evidencia clara respecto de los efectos de la diversificación de exportaciones (Cadot, Carrère y Strauss-Kahn 2011, 2013), mientras que hay fundamentos sólidos para sustentar políticas públicas enfocadas en potenciar el comercio internacional (Feenstra 2018; Costinot y Rodríguez-Clare 2018) y facilitar las exportaciones (Munch y Schaur 2018; Volpe y Carballo 2008). Por otro lado, la evidencia reciente sugiere que una estrategia de impulsar exportaciones más sofisticadas podría ser impracticable para países en desarrollo como Chile (Lectard y Rougier 2018).

Finalmente, dado que con una alta probabilidad la diversificación de exportaciones continuará siendo una preocupación en el debate público, se discuten dos alternativas de política pública que intentan conciliar los lineamientos encontrados en este artículo con un mayor grado de diversificación. La primera opción se refiere a promover la diversificación de exportaciones dentro de cada sector productivo, lo que permitiría potenciar los sectores que cuentan con ventajas comparativas al mismo tiempo que se aumentan las variedades exportadas. Otra opción se refiere a explotar las fortalezas institucionales que tiene Chile en materia económica para diversificarse hacia la exportación de servicios. Ambas políticas públicas podrían complementar una estrategia comercial centrada en el fomento y facilitación de exportaciones. 


\section{BIBLIOGRAFÍA}

Agosin, M.R., Álvarez, R. y Bravo-Ortega, C. 2012. Determinants of Export Diversification around the World: 1962-2000. The World Economy 35(3), 295315.

Banco Central de Chile 2020. Base de Datos Estadísticos. Disponible en: https:// www.bcentral.cl/areas/estadisticas [24 de julio 2020].

Banco Mundial 2020a. Doing Business. Disponible en: https://espanol.doingbusiness.org [24 de julio 2020].

Banco Mundial 2020b. World Development Indicators. Databank. Disponible en: https://databank.worldbank.org/reports.aspx? source=World-DevelopmentIndicators [24 de julio 2020].

Besedeš, T. y Prusa, T.J. 2011. The Role of Extensive and Intensive Margins and Export Growth. Journal of Development Economics 96(2), 371-379.

Bhattacharyya, S. y Hodler, R. 2010. Natural Resources, Democracy, and Corruption. European Economic Review 54(4), 608-621.

Boschini, A., Pettersson, J. y Roine, J. 2013. The Resource Curse and Its Potential Reversal. World Development 43, 19-41.

Briones, I. 2019. Quienes dicen que este gobierno renunció a sus convicciones deberían actualizar su mirada. Chile cambió radicalmente. La Tercera, 10 de noviembre. Disponible en: https://www.latercera.com/pulso/noticia/ ignacio-briones-quienes-dicen-este-gobierno-renuncio-convicciones-deberianactualizar-mirada-chile-cambio-radicalmente/894927/ [18 de julio 2020].

Briones, I. 2020. No sacamos nada con tener una carga tributaria de país desarrollado sin serlo. La Tercera, 2 de febrero. Disponible en: https://www. latercera.com/pulso/noticia/ignacio-briones-no-sacamos-nada-una-cargatributaria-pais-desarrollado-sin-serlo/996082/ [18 de julio 2020].

Cadot, O., Carrère, C. y Strauss-Kahn, V. 2011. Export Diversification: What's behind the Hump? Review of Economics and Statistics 93(2), 590-605.

Cadot, O., Carrère, C. y Strauss-Kahn, V. 2013. Trade Diversification, Income, and Growth: What do We Know? Journal of Economic Surveys 27(4), 790-812.

Cavalcanti, T.V., Mohaddes, K. y Raissi, M. 2015. Commodity Price Volatility and the Sources of Growth. Journal of Applied Econometrics 30(6), 857-873.

Coelli, T.J. y Rao, D.P. 2005. Total Factor Productivity Growth in Agriculture: A Malmquist Index Analysis of 93 Countries, 1980-2000. Agricultural Economics 32, 115-134.

Costinot, A. y Rodríguez-Clare, A. 2018. The US Gains from Trade: Valuation Using the Demand for Foreign Factor Services. Journal of Economic Perspectives 32(2), 3-24.

Chaney, T. 2008. Distorted Gravity: The Intensive and Extensive Margins of International Trade. American Economic Review 98(4), 1707-1721.

Chaney, T. 2018. The Gravity Equation in International Trade: An Explanation. Journal of Political Economy 126(1), 150-177. 
Feenstra, R.C. 2018. Alternative Sources of the Gains from International Trade: Variety, Creative Destruction, and Markups. Journal of Economic Perspectives 32(2), 25-46.

Feenstra, R.C., Inklaar, R. y Timmer, M.P. 2015. The Next Generation of the Penn World Table. American Economic Review 105(10), 3150-3182.

Feenstra, R.C. y Kee, H.L. 2008. Export Variety and Country Productivity: Estimating the Monopolistic Competition Model with Endogenous Productivity. Journal of International Economics 74(2), 500-518.

Fitch Ratings 2020. Sovereigns Report for Chile. Disponible en: https://www. fitchratings.com/search/?query=Sovereigns\%20Report $\% 20$ for $\% 20$ Chile [24 de julio 2020].

FMI (Fondo Monetario Internacional) 2019. World Economic Outlook (WEO) Database. Disponible en: https://www.imf.org/external/pubs/ft/weo/2019/02/ weodata/index.aspx [24 de julio 2020].

Giorgi, G.M. y Gigliarano, C. 2017. The Gini Concentration Index: A Review of the Inference Literature. Journal of Economic Surveys 31(4), 1130-1148.

Hausmann, R., Hwang, J. y Rodrik, D. 2007. What You Export Matters. Journal of Economic Growth 12(1), 1-25.

Johnson, R.C. 2014. Five Facts about Value-Added Exports and Implications for Macroeconomics and Trade Research. Journal of Economic Perspectives 28(2), 119-142.

Larraín, F. 2018a. Un camino de inversión, productividad y emprendimiento. Conferencia Ministerio de Hacienda, Chile.

Larraín, F. 2018b. Chile en marcha: un análisis del camino al desarrollo. Seminario, 14 de diciembre, Ministerio de Hacienda, Chile.

Larraín, F. 2019. Boosting and Modernizing the Chilean Economy. Conferencia, 15 de abril, Ministerio de Hacienda, Chile.

Larraín, F. y Perelló, Ó. 2019. Resource Windfalls and Public Sector Employment: Evidence from Municipalities in Chile. Economia 19(2), 127-167.

Larraín, F. y Perelló, Ó. 2020. Can Mining Countries Take Advantage of their Mining Rents? A Question of Abundance, Concentration, and Institutions. Oxford Development Studies 48(2), 148-165.

Lectard, P. y Rougier, E. 2018. Can Developing Countries Gain from Defying Comparative Advantage? Distance to Comparative Advantage, Export Diversification and Sophistication, and the Dynamics of Specialization. World Development 102, 90-110.

Lederman, D. y Klinger, B. 2006. Diversification, Innovation, and Imitation inside the Global Technological Frontier. The World Bank. Disponible en: https:// openknowledge.worldbank.org/handle/10986/8735?locale-attribute=fr [24 de julio 2020].

Martin, W. y Mitra, D. 2001. Productivity Growth and Convergence in Agriculture versus Manufacturing. Economic Development and Cultural Change 49(2), 403-422. 
Melitz, M.J. 2003. The Impact of Trade on Intra-Industry Reallocations and Aggregate Industry Productivity. Econometrica 71(6), 1695-1725.

Moody's Investors Service 2019. Credit Opinion. Disponible en: https://www. moodys.com/credit-ratings/Chile-Government-of-credit-rating-171693 [24 de julio 2020].

Munch, J. y Schaur, G. 2018. The Effect of Export Promotion on Firm-Level Performance. American Economic Journal: Economic Policy 10(1), 357-387.

Robinson, J.A., Torvik, R. y Verdier, T. 2014. Political Foundations of the Resource Curse: A Simplification and a Comment. Journal of Development Economics 106, 194-198.

Robinson, J.A., Torvik, R. y Verdier, T. 2017. The Political Economy of Public Income Volatility: With an Application to the Resource Curse. Journal of Public Economics 145, 243-252.

Sachs, J.D. y Warner, A.M. 2001. The Curse of Natural Resources. European Economic Review 45(4-6), 827-838.

Standards \& Poor 2019. S\&P Global Ratings. Disponible en: https://www.spglobal. com/ratings/en/index\#find_a_rating [24 de julio 2020].

UN Comtrade 2020. UN Comtrade Online Database. Disponible en: https:// comtrade.un.org/ [24 de julio 2020].

Volpe Martincus, C. y Carballo, J. 2008. Is Export Promotion Effective in Developing Countries? Firm-Level Evidence on the Intensive and the Extensive Margins of Exports. Journal of International Economics 76(1), 89106.

World Economic Forum 2019. Global Competitiveness Report: How to End a Lost Decade of Productivity Growth. Disponible en: https://es.weforum.org/reports/ how-to-end-a-decade-of-lost-productivity-growth [24 de julio 2020]. EP 